\title{
A risk map methodology to assess the spatial and temporal distribution of leakage into groundwater from Geologic Carbon Storage
}

Erica R. Siirila-Woodburn*, Abdullah Cihan, Jens T. Birkholzer

Energy Geosciences Division

Lawrence Berkeley National Laboratory

1 Cyclotron Road, M.S. 74R-316C

Berkeley, CA, USA 94704

*corresponding author: ERWoodburn@lbl.gov 


\begin{abstract}
The risks to potable aquifers due to brine leakage through plugged and abandoned (P\&A) wells is highly uncertain and a potentially significant contributor to the risk profile in Geologic Carbon Storage (GCS). This uncertainty stems from the unknown location of wells and the large variance of P\&A wellbore permeability, making the spatial assessment of P\&A brine leakage risk challenging. A new methodology is presented to generate "risk maps", or spatial distributions of brine leakage risk to groundwater resources as defined with no-impact or Maximum Contaminant Level (MCL) thresholds. The methodology utilizes probability theory, thereby avoiding the use of computationally expensive Monte Carlo simulations while maintaining flexibility in modeling techniques. These maps provide quantitative probabilities of risk as a function of time to inform site selection and monitoring during and post-injection, conducive to the US EPA's permitting of Class-VI wells and the so-called "area of review", AoR. As a demonstration of the methodology, a numerical model of a hypothetical fullycoupled system spanning from the injection reservoir to the USDW is used to assess the evolution of brine leakage through $\mathrm{P} \& \mathrm{~A}$ wells. Risk maps of $\mathrm{CO}_{2}$ leakage can also be generated with this methodology for a comprehensive assessment of GCS leakage risk.
\end{abstract}

\title{
Keywords
}

brine leakage; risk assessment; risk maps; geologic carbon storage; carbon capture and storage; $\mathrm{CO}_{2}$ injection; 


\section{Introduction}

Geologic Carbon Storage (GCS) may be a viable option to aid in mitigating climate change, and is frequently included in projections to reduce global $\mathrm{CO}_{2}$ emissions. The intergovernmental panel on climate change (IPCC) most recently planned that cost-effective fossil fuel power generation without the use of GCS will be entirely phased out by 2100 (IPCC, 2014). Although the emission reductions projected from GCS-inclusive strategies could be as high as $30 \%$ by 2050 (IEA, 2009), questions related to the safety of overlying drinking water aquifers still need addressing as potential leakage of $\mathrm{CO}_{2}$ and/or brine from deep geologic storage formations into groundwater resources may adversely affect water quality (Little and Jackson, 2010, Siirila et al., 2012, Navarre-Sitchler et al., 2013, Varadharajan et al., 2013, Carroll et al., 2014, Zhong et al., 2014, Zheng et al., 2015, Bacon et al., 2016, Carroll et al., 2016, Keating et al., 2016, Xiao et al., 2016).

As part of the protection of these freshwater resources, the US EPA has implemented permitting regulations for class-VI wells used to inject $\mathrm{CO}_{2}$ into deep storage formations. These regulations include the need to delineate a so called "area of review" (AoR), formally defined as the region surrounding the geologic sequestration project where underground sources of drinking water (USDWs) may be endangered by the injection activity (US EPA, 2013). Guidelines state that the AoR should encompass 1) the maximum extent of the $\mathrm{CO}_{2}$ plume and 2) the pressure front of sufficient magnitude required to force fluids from the injection zone into the formation matrix of the USDW over the lifetime of the project, the latter of which is typically larger in extent than the former for industrial-scale injections (Bandilla et al., 2012; Birkholzer et al., 2014). 
Assuming hydrostatic conditions, a worst-case brine leakage scenario is used in the Class-VI well permitting to determine the extent of the differential pressure front covering an area within which differential pressures exceed a critical differential pressure sufficient in magnitude to force fluids from the injection zone into the USDW via an open-wellbore conceptual model. The calculated critical differential pressure for open conduit flow from the injection zone upwards towards the USDW is a function of temperature and salinity variations (Birkholzer et al., 2011), and thus in an injection reservoir with relatively low-salinity brine, even small pressure increases at several kilometers distance from the injection location may result in USDW leakage via a potential open-wellbore. The AoR calculated using the proposed method by the US EPA's class-VI regulation (US EPA, 2013) is arguably over-conservative, as open-wellbores are an extreme risk scenario, and may not be a representative characterization of more likely wellbore leakage risks such as leakage in and around the damage zones of plugged and abandoned wells (Celia et al., 2004). As pointed out by Birkholzer et al. (2014), the presence of thief zones (i.e. brine-bearing intermediate layers between the USDW and the injection reservoir) can prevent brine leakage into the USDW by laterally mitigating the vertical flow of brine through and around the wellbore casing. Also, the inherent assumption of a hydrostatic equilibrium between the injection reservoir and the USDW in the US EPA's suggested method of critical pressure calculation may not be valid in some reservoir systems (US EPA, 2013 p. 42; Oldenburg et al., 2016), requiring the development of more general and robust methods for AoR delineation.

Birkholzer et al. (2014) presented an alternative, tiered AoR methodology which differentiates GCS leakage risks by constituent $\left(\mathrm{CO}_{2}\right.$ or displaced brine from the injection reservoir) and the type of leakage pathway (plugged and abandoned or open wellbores). They 
proposed a three-tier AoR system to differentiate these types of risks. The first tier of AoR is defined by the spatial extent over which the $\mathrm{CO}_{2}$ plume exists, and $\mathrm{CO}_{2}$ leakage could occur. Similarly, a second tier of AoR is defined by the spatial extent over which the pressure front is sufficiently large enough to result in brine leakage into the USDW via open-boreholes (i.e. the proposed method in the US EPA's class-VI regulation). Finally, a third tier of AoR is defined as the intermediate area between Tier 1 and 2 where brine leakage could occur via plugged and abandoned (P\&A) wellbores. The spatial extent of Tier 2 AoR can be estimated via simple analytical and semi-analytical equations and some knowledge of the initial fluid pressure in the USDW and injection zone, density and temperature variations, and depth between the USDW and injection reservoir (see US EPA, 2013; Nicot et al., 2008; Birkholzer et al., 2011). As shown in Figure 1a, estimating the spatial extents of AoR Tiers 1 and 2 is fairly straightforward (provided that reliable predictions of future $\mathrm{CO}_{2}$ migration and reservoir pressurization are available) whereas a risk-driven methodology to determine the spatial extent of the Tier 3 AoR has yet to be developed.

Here we present a methodology that appropriately differentiates the risks related to geologic carbon storage while providing an approach to quantify the spatial extents of brine leakage risk through P\&A wells. This approach also considers the substantial uncertainty due to varying wellbore hydraulic properties along the leakage pathway. Because the area where brine leakage through P\&A wells could occur is likely expansive in spatial extent, the presented methodology incorporates a way to determine how risk evolves as a function of lag distance from the injection well, thus the term "risk maps." It also integrates time as a dimension in the methodology, allowing for risk assessors and other stakeholders to determine not only the spatial but also the temporal evolution of risk. The concept of spatially distributed risk has been applied 
in a number of different disciplines such as the spread of invasive species (e.g. Hulme, 2009, Venette et al., 2010), the spread of diseases (e.g. Moffett et al., 2007, Boender et al., 2007), and for natural hazards (e.g. Gaull et al., 1990, Douglas, 2007). The presented method of generating risk maps is flexible in techniques used (numerical versus analytical) and is computationally very efficient, stemming from probability theory rather than computationally expensive Monte Carlo simulations. While advances in quasi-Monte Carlo and Latin Hypercube Sampling have recently been made in the realm of $\mathrm{CO}_{2}$ storage to greatly reduce computational demands in some appliations (e.g. Hou et al., 2016, Pawar et al., 2016), the computational efficiency of our approach allows for higher fidelity models and more complexity to be integrated into the risk assessment framework. Lastly, although we present the probabilistic methodology applied to the assessment of brine leakage via P\&A wells, the same set of steps in the risk map procedure may be used to assess both $\mathrm{CO}_{2}$ leakage and brine leakage via open-borehole wells. It may also be applied to assess leakage where reservoir conditions prior to injection are not in equilibrium.

\section{Construction of Risk Maps: Methodology}

Figure $1 \mathrm{~b}$ shows the conceptual model used to generate risk maps for brine leakage via P\&A wells. $\mathrm{CO}_{2}$ is injected beneath a deep, low permeability caprock layer into an injection reservoir which leaky wells may penetrate. In the region between Tier 1 and Tier 2 AoR, the two greatest sources of uncertainty are assumed to be the unknown location of the leaky well and the leaky well's permeability, which can range over several orders of magnitudes. The first step in the calculation of a risk map used to define Tier $3 \mathrm{AoR}$ is to determine leakage at a discrete number of lag distances between Tiers 1 and 2. In Figure 1b, this is shown as example leaky wells labeled $\mathrm{W}_{1}, \mathrm{~W}_{2}$, and $\mathrm{W}_{3}$. These can be thought of as the "sampled" leaky well locations, 
where the calculations are performed. The method can be applied for complex anisotropic and heterogeneous systems. However, if the assumption of homogeneous, isotropic layers is made (i.e. that the USDW, thief and caprock zones, and injection reservoir do not contain significant heterogeneity below the strata-scale) then calculations only need to be performed along one direction, where the leaky well location increases as a function of distance from the injection well. Then, a radial extrapolation can be performed in the x-y plane. In the example shown in

Figure $1 \mathrm{~b}$, leakage at well $\mathrm{W}_{1}$ is equivalent to leakage at well $\mathrm{W}_{4}$. Then, leakage at well $\mathrm{W}_{5}$ can be interpolated from wells $\mathrm{W}_{1}$ and $\mathrm{W}_{2}$. As described below, leakage amounts at the discrete leaky well locations (e.g. $\mathrm{W}_{1}, \mathrm{~W}_{2}, \mathrm{~W}_{3}$ in Figure 1 ) are used to quantify the uncertainty of P\&A leakage as a function of distance from the injection well. Note that the topic of well interference where multiple wells may be leaking simultaneously is not considered here, and is the topic of future work.

\subsection{Simulations}

As shown in Figure 2, the first step of the risk map methodology begins with the calculation of brine leakage through $\mathrm{P} \& \mathrm{~A}$ wells as a function of time and at increasing distances away from the injection. This can be solved numerically, or if density differences are neglected, with analytical methods. Once discrete lag locations are selected, brine leakage is calculated over a range of effective well permeabilities, where the permeability of the well does not vary in the vertical direction. Unlike computationally expensive Monte Carlo simulations that would randomly sample hundreds or more of effective well permeabilities for each location, the risk map methodology only requires data for a small and discrete number of effective well permeability values for each location. For example, a typical risk map calculation with simple 
homogenous and isotropic layers would only require on the order of tens of leaky well locations and tens of permeability values, typically with less than 100 total simulations. As further described in Section 2.3, a probabilistic theory approach other than Monte Carlo simulations is used to alleviate the need for additional computations in this step.

From Step 1, a number of output metrics can be compared. To assess the risk to potable drinking water resources, two practical parameters for analysis are the volume and the area of groundwater impacted by leaky wells. For sake of terminology, we will refer to the volume or area of impacted water as the parameter of interest hereafter. Consistent with a "no-impact" regulation, if brine leakage into the USDW causes the parameter of interest to be greater than changes that would be observed due to the natural variability of the system, there is nonnegligible risk and action (such as decontamination efforts or a cease of injection) must occur (Carroll et al., 2014; Last et al., 2016, Xiao et al., 2016). An alternative to the no-impact regulation is based on the EPA's secondary Maximum Contaminant Level (MCL) limits for groundwater concentrations. For total dissolved solids, water with an aqueous concentration over $500(\mathrm{mg} / \mathrm{L})$ pose adverse water quality properties such as a salty taste, irregular color, and the potential for staining. We define risk in the USDW to be non-zero if the parameter of interest exceeds either of these thresholds (i.e. the no-impact or MCL), but of course any other reasonable thresholds could be selected instead. The parameter of interest is then assessed as a function of the following: distance from the injection well, permeability of the well, and time. Of specific importance is the relationship between the parameter of interest as a function of well permeability, as discussed in the following section.

\subsection{Determination of Parameter Distributions}


The relationship between the parameter of interest and well permeability $\left(k_{w}\right)$ will be specific to a certain distance from the injection well as imposed in Step 1 of the risk map methodology. As shown in Figure 2 (Step 1), leakage rates and the subsequent volumes of impacted water at $n$ wells between AoR 1 and 2 were calculated as a function of time. Using the impacted volume of water $\left(\operatorname{Vol}_{i m p}\right)$ as an example of the parameter of interest, the relationship between $\operatorname{Vol}_{i m p}$ and $k_{w}$ is fit to a function at each lag distance from the injection well and at each point in time (see Figure 2 Step 2). The function $\operatorname{Vol}_{i m p}\left(k_{w}\right)$ is required to be monotonic and invertible. As shown in section 5, our numerical results from the coupled reservoir-USDW system indicate that Volimp $_{\text {in }}$ as a function of $k_{w}$ follows a clear, monotonically increasing trend which can be mathematically represented by simple empirical functions. As one example, we selected a Gaussian type function satisfying monotonicity and invertibility. The method also requires knowledge of the probability distribution function for $k_{w}$. Unfortunately, field measurements of effective permeabilities along P\&A wells are very limited; measured values reported from field studies vary between $10^{-15} \mathrm{~m}^{2}-10^{-12} \mathrm{~m}^{2}$ (e.g. Crow et al., 2010; Duguid et al., 2011, Gasda et al., 2013, Duguid et al., 2013). Additionally, there are also only a sparse number of studies in the literature that present frequency distributions for effective well permeabilities (e.g., Nordbotten et al., 2009; Celia et al., 2011; Checkai et al., 2013), generally represented by using lognormal or bilognormal frequency distribution functions. The effective well permeability ranges in these studies were inferred based on soft data such as well construction characteristics, drilling time (e.g., Watson and Bachu, 2008, 2009; Celia et al., 2011) as well as pressure-time data in annulus and flow rate measurements in oil/gas wells (e.g., Checkai et al., 2013). A strength of the risk map methodology presented here is that it takes into account the uncertainty related to the distribution of $k_{w}$. 


\subsection{Generation of Probability Distribution of Parameter of Interest}

Step 3 of the risk map methodology is to obtain the spatially-dependent probability of the parameter of interest (following the example in Figure 2, $V_{i m p}$ ). To do so, we propose an alternative to the Monte Carlo-based approach based on a probability theory. The functions of a random variable method can be used to obtain a cumulative probability of a continuous random variable based on the relationship between that variable and another random variable of which the probability distribution function is known. Stated more formally for Tier 3 AoR, if $k_{w}$ is a continuous random variable with probability density $f_{k_{w}}\left(k_{w}\right)$ and the relationship between Vol $_{i m p}$ and $k_{w}$ can be described by a continuous, increasing function of $k_{w}$ defined by:

$$
v_{\text {twe: }}-u\left(k_{n}\right)
$$

and if this function is invertible, then:

$k_{,}-\mathrm{r}\left(\mathrm{Hol} \boldsymbol{w}_{\mathrm{sep}}\right)$

and the probability density function for $V o l_{i m p}$ based on $f_{k_{w}}\left(k_{w}\right)$ is given by:

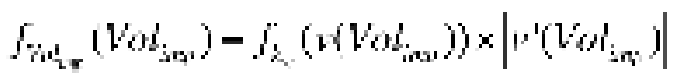

Then, the cumulative probability distribution can be expressed as:

$$
F\left(V o l_{\text {imp }}\right)={ }_{0}^{{ }^{V o l} l_{i m p}} f_{\text {Vol limp }}() d
$$

Equation (4) represents the probability that the impacted volume of the USDW is less than or equal to $\operatorname{Vol}_{\text {imp }}$, where $\square \square$ is a dummy (or a numeric proxy stand-in) variable.

By repeating the above steps for each lag and as a function of time, the spatial probability of exceeding the parameter of interest is determined (see Figure 2, Step 3). Then, by setting a threshold of acceptable risk, such as zero contamination or a small, acceptable volume of 
impacted water, probabilities can be mapped onto an x-y space, thereby generating a "risk map." As shown in Figure 2 Step 4, these maps are descriptions of the probability of exceeding a certain threshold of $V_{o l} l_{i m p}$ (i.e., equal to $1-F\left(V_{o l} l_{i m p}\right)$ ) based on the uncertainty stemming from $k_{w}$. Because these maps are probabilistic in nature and can show how a risk profile evolves over time, their use in site selection, monitoring, and potential remediation is very valuable. A demonstration of the four steps in the risk map methodology is outlined in section 3 , verified with another method in section 4, and discussed in section 5 .

\section{Example Demonstration}

A hypothetical $\mathrm{CO}_{2}$ injection site where brine leakage through $\mathrm{P} \& \mathrm{~A}$ wellbores may occur is used to demonstrate the use of risk maps in Tier 3 AoR. To account for density driven flow due to the influence of brine, numerical simulations are performed with an aqueous variable density and viscosity numerical simulator. Since our focus is on brine leakage risks in areas beyond the $\mathrm{CO}_{2}$ plume zone (Tier 1, Figure 1a), a single-phase flow simulator is used to represent $\mathrm{CO}_{2}$ injection by an equivalent volume of brine. By doing so, pressure perturbations and brine leakage phenomena in leaky wells beyond the Tier 1 zones are modeled without taking into account the local two-phase flow processes, as has been done and justified in earlier studies (Nicot, 2008; Cihan et al., 2013). The potential for $\mathrm{CO}_{2}$ leakage to occur is restrained to an area encompassing Tier 1 only, which can be evaluated separately using a two-phase flow simulator without the computational demands of the wellbore brine leakage simulation. Three-dimensional numerical simulations are performed using an in-house code, which solves the continuity and advection diffusion equations for a single-phase binary mixture of $\mathrm{NaCl}-\mathrm{H}_{2} \mathrm{O}$ based on a finite volume method. Properties of the mixture (compressibility, density and viscosity) are computed 
as a function of salt mass fraction, pressure and temperature, using the correlations developed by Spivey et al. (2004) and Philips et al. (1981). Static spatial temperature variation is accounted for with depth, but dynamic heat flow is not simulated. This code has been verified by analytical and numerical simulations, and has also been shown to represent experimental observations reasonably well under ambient conditions for brine flow in laboratory tests (Agartan et al., 2015).

Parameterization of the different system components for a hypothetical, yet realistic coupled GCS system (including the reservoir, caprock, USDW, and leaky well) is outlined below. The simulated domain consists of a $60(\mathrm{~m})$ thick storage reservoir overlain by a $1025(\mathrm{~m})$ thick lowpermeability caprock and a $35(\mathrm{~m})$ thick fully saturated USDW. The spatial extent of the fully coupled system is $75(\mathrm{~km})$ in the $\mathrm{x}$-direction, $50(\mathrm{~km})$ in the y-direction, and $1.12(\mathrm{~km})$ in the $\mathrm{z}$ direction. Finer cell-discretization with less than $0.5(\mathrm{~m})$ grid size is used near the injection and leaky well locations, with larger cells away from the wells to accommodate the large spatial extents in the $\mathrm{x}$ and $\mathrm{y}$ directions. Figure 3 shows an example domain discretization for a leaky well location at $\mathrm{x}=5(\mathrm{~km})$. Vertical cell discretization is also shown in Figure 3 (right), which is constant for all simulations. Table 1 details the hydrologic parameters of each unit of the domain. The storage reservoir is characterized by a background salinity of $1195\left(\mathrm{~kg} / \mathrm{m}^{3}\right)$, the USDW by zero salinity, and the caprock zone between the reservoir and the USDW of varied salinity decreasing linearly from the top of the reservoir to the bottom of the USDW.

Temperature follows a geothermal gradient of $25^{\circ} \mathrm{C}$ per $\mathrm{km}$ (see Table 1). For all simulations, $\mathrm{CO}_{2}$ is injected into the storage reservoir via a single well at a rate of $2(\mathrm{Mt} / \mathrm{y})$ for 30 years (see Table 1 for parameterization used to calculate brine equivalent injection). The location of the $\mathrm{CO}_{2}$ injection well into the reservoir formation $1,060(\mathrm{~m})$ beneath the land surface is constant in 
all simulations (see Figure 3). Brine leakage into the USDW via P\&A wellbores is tracked as a function of time for 200 years (including injection time) at ten increasing lag distances between the injection well and the leaky well. Leaky wells are spaced laterally away from the injection well in $2(\mathrm{~km})$ increments in the $\mathrm{x}$-direction along one line in the y-direction. Following the notation in Figure 3, leaky wells are located at $x-W_{1}=5 \mathrm{~km}, \mathrm{x}-\mathrm{W}_{2}=7 \mathrm{~km}, \ldots, \mathrm{x}-\mathrm{W}_{10}=23 \mathrm{~km}$ and $\mathrm{y}-\mathrm{W}_{1-10}=0 \mathrm{~km}$ in all simulations.

As described in Section 2.1, unlike computationally expensive Monte Carlo simulations, this methodology only requires simulations for a small set of discrete intervals of well permeability. In this demonstration, leaky well permeability was varied from $10^{-8}\left(\mathrm{~m}^{2}\right)$ to $10^{-13}\left(\mathrm{~m}^{2}\right)$ in oneorder-of-magnitude increments. Thus, only a total of 60 simulations (10 leaky well locations and 6 leaky well permeability values) are needed for each demonstration of the methodology. The discrete leaky well permeability values and increments should be selected with some knowledge of the shape and distribution of the well permeability probability distribution. For example, a complexly-shaped probability distribution function may require additional discrete leaky well permeability values, and at smaller intervals. Given that this work is focused on describing the theory of the risk map methodology, we reserve the sensitivity of well permeability selection for a future study. No-flow boundaries cover all external faces of the domain so that a gradient does not exist, and simulation begins injection from hydrostatic conditions.

For demonstration purposes, we chose to use the impacted volume of USDW water, Vol imp, $_{\text {, }}$ as the parameter of interest, although the area of impacted USDW or a similar metric is equally as valid or possible. In the demonstration, $V o l_{i m p}$ is defined as any pore space volume above the US EPA's secondary MCL for total dissolved solids, $500(\mathrm{mg} / \mathrm{L})$, calculated at each time by summing cell-volumes above this threshold, multiplied by the USDW porosity. From the results 
of the numerical simulations, the relationship between $V o l_{i m p}$ and $k_{w}$ is fit to a unit-step Gaussian function with high accuracy, as discussed in section 5.2. A hypothetical distribution of well permeability is assumed to follow a generalized lognormal distribution (Diamond and Dolch, 1972), which is represented by:

$f_{k_{w}}\left(k_{w}\right)=\frac{1}{\sqrt{2 \pi} \ln \sigma} \exp \left[-\left(\frac{\ln \left(k^{\prime} / \mu\right)}{\sqrt{2} \ln \sigma}\right)^{2}\right]$

where $k^{\prime}=\left(k_{w}-k_{\min }\right)\left(k_{\max }-k_{\min }\right) /\left(k_{\max }-k_{w}\right)$, and $\sigma$ and $\mu$ are the statistical parameters

characterizing the probability distribution of $k^{\prime}$. The cumulative distribution function for $k_{w}$ can be expressed as:

$F_{k_{w}}\left(k_{w}\right)=\frac{1}{\sqrt{2} \ln }{ }_{k_{w}}^{k_{\max }} \exp \frac{\ln k^{\prime}() \ln }{\sqrt{2} \ln } \div \frac{2}{\left(k_{\max }\right)\left(k_{\max }\right)} d$

In this demonstration example, we selected $\mu=10^{-12}\left(\mathrm{~m}^{2}\right), \sigma=2.8$, and lower and upper cut-off values of $k_{\min }=10^{-22}\left(\mathrm{~m}^{2}\right)$ and $k_{\max }=10^{-9}\left(\mathrm{~m}^{2}\right)$, respectively. The generalized lognormal well permeability distribution used in this demonstration is shown as a cumulative distribution function in Figure 4. Sensitivity of the well permeability distribution on the risk map evolution is not discussed here, and is the subject for future work.

\section{Methodology Verification}

Using the conceptual model of the demonstration example described in Section 3, a semianalytical mathematical model by Cihan et al. (2011) is used to compare the generated risk map results using 1) the functions of a random variable methodology with discrete sub-sample of well permeability simulations and 2) Monte Carlo simulations for 100 realizations of well permeability values for each lag distance. 
Figure 5 shows a 1D transect of the probabilistic risk map obtained with the two methods a) at the end of injection (30 y) and b) at $200(y)$. These 1D transects of the risk map reflect one radial direction along the $2 \mathrm{D}$ risk map, as shown in Figure 2, Step 4. Symbols show results obtained with Monte Carlo simulations and lines show results obtained with the functions of a random variable method. Colors denote different threshold $(T)$ volumes of $V_{\text {imp }}$, ranging from $T$ $=10^{0}-10^{3}\left(\mathrm{~m}^{3}\right)$. As shown in Figure 5, the probabilities as a function of distance trends are in agreement for the two solutions, especially at the higher and lower threshold values $\left(T=10^{3}\right.$ and $10^{0}\left(\mathrm{~m}^{3}\right)$, respectively), justifying the use of the more computationally efficient functions of a random variable method in the risk map approach. This approach's computational efficiency compared to the Monte Carlo simulations comes from the need to conduct a significantly less number of forward simulations to generate the impacted volume of USDW water with brine leakage. For the simple example here, the Monte Carlo simulation-based method uses 1000 simulations in total, while the functions of a random variable method uses only 70 simulations. For even more complex systems such as for highly heterogeneous reservoir conditions, leakage calculations may need to be conducted for many more spatial potential leakage paths in order to generate risk map contours at a sufficiently high resolution. In most cases uncertainty related to the properties of the reservoir system may require multiple realizations of the USDW and/or reservoir systems via geostatistical methods. In such a case, the number of simulations required can drastically increase the calculation's computational expense. Thus, the possibility of using higher fidelity simulators in conjunction with traditional Monte Carlo simulations to determine wellbore leakage can quickly become prohibitive for the generation of risk maps, making the functions of a random variable approach an attractive alternative. 


\section{Results and Discussion}

\subsection{Mass Flow Rate into the USDW and $V_{\text {imp }}$ as a Function of Time}

For the 60 numerical simulations described in Section 3, vertical mass flow rates in the leaky well at the interface between the caprock unit and the USDW are tracked as a function of time throughout the 200 (y) simulation. While the parameter of interest in this demonstration is the volume of impacted USDW water above the $500(\mathrm{ppm})$ threshold, information concerning mass flow rates when significant brine is leaking into the USDW may be important in terms of monitoring and risk management schemes. In this demonstration (and at this injection rate of 2 $\mathrm{Mt} / \mathrm{y})$ leakage rates into the USDW are only significant between approximately simulation years 15 and 34. Figure 6 shows an example of mass flow rate results for the well permeability equal to $10^{-9}\left(\mathrm{~m}^{2}\right)$ for leaky well lag distances $1-10$. This result is important because GCS $\mathrm{CO}_{2}$ injections resulting in USDW contamination of brine may not be detectable for substantial periods of time, in this example for over one or two decades after the onset of injection. Additionally, after injection ceased at year 30, leakage continued to be substantial for the following 3-4 (y), depending on the distance from the injection well.

Although mass leakage rates are only detectable during a short window of the simulation, once brine enters the USDW a density-dependent plume advects and disperses over time. In this demonstration, the brine plume in the USDW continues to grow past the end of injection at 30 (y) for all simulations. The volume of impacted water, $V_{\text {imp }}$, grows throughout the entire duration of the 200 (y) simulation for the higher leaky well permeabilities (see Figure 7a) but decreases over time towards zero for lower leaky well permeabilities (see Figure $7 b$ ). The latter is a result of relatively small quantities of brine leakage into the USDW when the leaky well permeability is low (note the y-axis differences in Figure 7a) and 7b) and the subsequent dilution of the brine 
plume with non-saline USDW water. It is interesting to note that for even small quantities of $V_{\text {imp }}$ (such as when the leaky well permeability is low) this dilution factor may require several decades or in some cases over a century to return the USDW back to pre-injection conditions (see Figure 7b). Recall that the simulated aquifer is not subject to a flow gradient, one contributing factor to long dilution times.

\subsection{Functional fit of Vol $_{\text {imp }}$ and $k_{\text {well }}$}

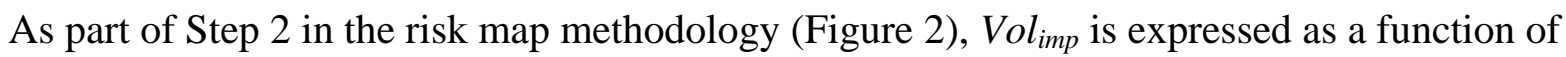
$k_{w}$ for each leaky well lag distance. The impacted volume of the aquifer as a function of the well permeability was found to follow the following distribution for most lag distances and for most times:

$\operatorname{Vol}_{\text {imp }}\left(k_{w}\right)=\frac{\exp (a)}{2} \operatorname{erfc}\left[\begin{array}{lll}\left(\log _{10} k_{w}\right. & b) / c\end{array}\right]\left(\log _{10} k_{w} \quad d\right), k_{\min } k_{w} \quad k_{\max }$

where $a, b, c$, and $d$ are parameters determined by fitting equation (7) to the simulated $V o l_{i m p}$ values. $\Gamma$ represents the unit step function, equal to 1 for $\log _{10} k_{w} \geq d$, or else equal to 0 . The coefficient of determination $\left(R^{2}\right)$ for the functional fit of $V o l_{i m p}$ and $k_{w}$ using equation (7) is very close to unity (>0.99) for nearly all simulations, ensuring an excellent fit. An example of this optimized functional fit is shown in Figure 8 for one point in time, at the end of the $30(\mathrm{y})$ injection. $V_{\text {imp }}$ results from the simulation are shown as symbols and the optimized functional fits are shown as solid lines for different distances from injection.

\subsection{Spatially-dependent probability distributions of Vol $_{\text {imp }}$}


The third step of the risk map methodology (see Figure 2) is to utilize the theory of functions of a random variable to generate the likelihood of exceeding $\operatorname{Vol}_{i m p}$ for the different leaky well locations. Following equations 1-4, cumulative distribution functions (CDFs) for each leaky well lag distance were calculated at every point in time. Figure 9 shows an example CDF of $V_{i m p}$ for different leaky well distances at the end of injection (30 y). As expected, wells closer to the injection point (e.g. well $\mathrm{W}_{1}$ ) exhibit a higher probability of exceeding a given value of impacted water when compared to wells farther from the injection point (e.g. well $\mathrm{W}_{10}$ ). In the example shown in Figure 9, the probability of exceeding a threshold equal to $10^{2}\left(\mathrm{~m}^{3}\right)$ of contaminated water for leakage at well $\mathrm{W}_{10}$ is less than $8 \%$; in contrast, the probability of exceeding the same threshold at well $\mathrm{W}_{1}$ is approximately $95 \%$.

An alternative way to interpret Figure 9 is that for a given likelihood of contamination, the impacted volume of USDW water can be predicted depending on the distance from the injection well. For example, at a distance of $23(\mathrm{~km})$ away from injection a 50\% chance of contamination would result in less than $20 \mathrm{~m}^{3}$ impacted water but that it's just as likely that at a distance of 5 $(\mathrm{km})$ from injection, impacted water would be over two orders of magnitude larger in volume. These types of assessment are extremely useful for site managers who can quantitatively assess the likelihood and quantity of contamination based on different acceptable degrees of contamination, distance from the injection site, and as a function of time.

\subsection{Probabilistic Risk Maps}

The final step in the risk methodology process is the visual representations of risk probabilities evolving over distance and time (Step 4, Figure 2). Risk maps are useful in both determining and developing an understanding of the given site's risk profile. In this 
demonstration, probabilities from the CDFs generated in Section 5.3 were extracted and plotted as a function of distance in Figure 10. Additionally, risk maps are shown for times before injection ceases ( $15 \mathrm{y}$ ) and post-injection (45 and $200 \mathrm{y}$ ). If a value of acceptable contamination is determined to be "de-minimis", or an acceptable risk too low of societal concern, this value can be used as the $V_{i m p}$ threshold. Figure 10 follows the example from Section 5.3 of a $V_{i m p}$ threshold equivalent to $T=10^{2}\left(\mathrm{~m}^{3}\right)$. During early times, results show that risk is low since the probability of $V_{\text {imp }}$ exceeding the threshold $T=10^{2}\left(\mathrm{~m}^{3}\right)$ is less than $0.2(-)$ for most of the Tier 3 areas calculated in this demonstration. As shown in Figure 10, the radial distances from injection between 5 and $23 \mathrm{~km}$ were chosen as spatial limits given that the range of risk values varied most significantly over these distances. As the injection continues on and leakage continues (see Figure 6), risk increases closest to the injection well. Post-injection, the probability of exceeding the threshold $T=10^{2}\left(\mathrm{~m}^{3}\right)$ becomes larger, and finally at $200(\mathrm{y})$ is nearly certain, $\mathrm{P}\left(V_{i m p}>T\right)=1$, for all lag distances from the injection well. Risk maps as shown in Figure 10 can be repeated for several different values of $T$ and then compared. For radially symmetric systems, risk maps are most easily compared as an abstraction in one dimension, as already done in the verification exercise shown in Figure 5.p

Figure 11 shows the same temporal and spatial evolution of the risk profile shown in Figure 10 along a 1-D transect of the risk map for various values of $T$ ranging from $10^{0}\left(\mathrm{~m}^{3}\right)$ to $10^{4}\left(\mathrm{~m}^{3}\right)$. The associated probabilities of exceeding low $T$ values such as $T=10^{0}\left(\mathrm{~m}^{3}\right)$ are initially less than unity at early times (Figure 11a) but become nearly certain as time increases (Figure 11b-d). Similarly, the associate probabilities of exceeding higher values of $T$ such as $T=10^{4}\left(\mathrm{~m}^{3}\right)$ are initially zero but become non-zero as the USDW brine plume grows over time. For example, at 45 (y) (Figure 11c) the probability of exceeding the $T=10^{4}\left(\mathrm{~m}^{3}\right)$ threshold is small (less than 
5\%) for distances 5-8 (km) from the injection well. Over the course of an additional $155(\mathrm{y})$ the probability of exceeding this threshold grows to distances of 5-17 $(\mathrm{km})$ from the injection well, with likelihoods as high as $20 \%$ at the shortest lag distances (Figure 11d).

\section{Conclusions}

An efficient new methodology to assess the spatial distribution pattern of leakage risk associated with Geologic Carbon Storage was presented and verified. A demonstration assessing brine leakage through plugged and abandoned wellbores, a significant contributor to the uncertainty of the risk profile in Geologic Carbon Storage, was shown. The result of this methodology are quantitative "risk maps", showing the spatial distributions of brine leakage risk through plugged and abandoned wells defined with no-impact or Maximum Contaminant Level (MCL) thresholds in underground sources of drinking water (USDW). These maps utilized probability theory without the use of computationally expensive Monte Carlo simulations while providing probabilities of risk to inform site selection and monitoring during and post-injection, conducive to the US EPA's permitting of class-VI wells and the area of review. Results show that by using this methodology, the probabilities of exceeding a given impacted volume or area of USDW water can be compared as a function of distance from the injection, time, and different thresholds of water quality.

Future work includes a comparison of different conceptual models of the reservoir and USDW system, such as the inclusion (and potentially subsequent reduction) of risk given intermediate brine-bearing formations (i.e., thief zones) in between the storage reservoir and the USDW. Other topics of future work include: the sensitivity of the well permeability distribution on risk map evolution such as the parameterization affecting the well permeability distribution 
shape and uncertainty, the effect of multiple leaky wells opposed to a single one and the impact on well interference, and the impact of risk mitigation on the risk map profile such as the repair of an abandoned well after leakage was detected.

\section{Acknowledgements}

This material is based upon work supported as part of Berkeley Lab's National Risk Assessment Partnership (NRAP) effort, supported by U.S. Department of Energy, Office of Fossil Energy, Office of Sequestration, Hydrogen, and Clean Coal Fuels, through the National Energy

Technology Laboratory, under Award Number DE-AC02-05CH11231.

\section{References}

Agartan, E., A. Cihan, T. H. Illangasekare, J. Birkholzer, and Q. Zhou, (2016), Mixing and Trapping of Dissolved $\mathrm{CO}_{2}$ in Deep Geologic Formations with Shale Layers, under review.

Bacon, N. P., Z. Qafoku, Dai, E.H. Keating, C.F. Brown, (2016), Modeling the impact of carbon dioxide leakage into an unconfined, oxidizing carbonate aquifer, International Journal of Greenhouse Gas Control, 44, 290-299, ISSN 1750-5836, doi:10.1016/j.ijggc.2015.04.008.

Bandilla, K.W., S.R. Kraemer, J.T. Birkholzer, (2012), Using Semi-analytical Solutions to Approximate the Area of Potential Impact for Carbon Dioxide Injection, International Journal of Greenhouse Gas Control, 8, 196-204. 
Bandilla, K.W., M.A. Celia, J.T. Birkholzer, A. Cihan, E.C. Leister, (2015), Multiphase Modeling of Geologic Carbon Sequestration in Saline Aquifers. Groundwater, 53: 362377. doi:10.1111/gwat.12315.

Birkholzer, J.T., J.P. Nicot, C.M. Oldenburg, Q.Zhou, S. Kraemer, K.W. Bandilla, (2011), Brine Flow up a Borehole Caused by Pressure Perturbation from $\mathrm{CO}_{2}$ Storage: Static and Dynamic Evaluations, International Journal of Greenhouse Gas Control, 5(4), 850-861.

Birkholzer, J., A. Cihan, K. Bandilla, (2014), A tiered area-of-review framework for geologic carbon sequestration. Greenhouse Gas Sci Technol, 4: 20-35. doi:10.1002/ghg.1393.

Boender, G.J., T.J. Hagenaars, A. Bouma, G. Nodelijk, A.R.W. Elbers, M.C.M de Jong, M. van Boven, (2007), Risk Maps for the Spread of Highly Pathogenic Avian Influenza in Poultry. PLoS Comput Biol 3(4): e71. doi:10.1371/journal.pcbi.0030071

Carroll, S., J. William Carey, D. Dzombak, N.J. Huerta, L. Li, T. Richard, W. Um, S.D.C. Walsh, L. Zhang, (2016), Review: Role of chemistry, mechanics, and transport on well integrity in $\mathrm{CO}_{2}$ storage environments, International Journal of Greenhouse Gas Control, 49, 149-160, 10.1016/j.ijggc.2016.01.010.

Carroll, S. A., E. Keating, K. Mansoor, Z. Dai, Y. Sun, W. Trainor-Guitton, C. Brown, D. Bacon, (2014). Key factors for determining groundwater impacts due to leakage from geologic carbon sequestration reservoirs. International Journal of Greenhouse Gas Control 29: 153-168.

Celia, M.A., S. Bachu, J.M. Nordbotten, S.E. Gasda, H.K. Dahle, (2004). Quantitative Estimation of $\mathrm{CO}_{2}$ Leakage from Geological Storage: Analytical Models, Numerical Models, and Data Needs, Proc. GHGT-7 Meeting, Vancouver, September 2004. 
Celia, M.A., J.M. Nordbotten, B. Court, M. Dobossy, S. Bachu, (2011). Field-scale Application of a Semi-Analytical Model for Estimation of $\mathrm{CO}_{2}$ and Brine Leakage Along Old Wells, International Journal of Greenhouse Gas Control, 5, 257-269.

Checkai, D., S. Bryant, Q. Tao, (2013). Towards a Frequency Distribution of Effective Permeabilities of Leaky Wellbores, GHGT-11 Proceedings of the 11th International Conference on Greenhouse Gas Control Technologies, 18-22 November 2012, Kyoto, Japan, Energy Procedia, 37, 5653-5660. http://dx.doi.org/10.1016/j.egypro.2013.06.487.

Cihan, A., Q. Zhou, and J. T. Birkholzer, (2011). Analytical solutions for pressure perturbation and fluid leakage through aquitards and wells in multilayered-aquifer systems. Water Resour. Res., 47, W10504, doi:10.1029/2011WR010721.

Crow, W., J.W. Carey, S. Gasda, B. Williams, M.A. Celia, (2010), Wellbore integrity analysis of a natural $\mathrm{CO}_{2}$ producer, Int. J. Greenhouse Gas Control, 4, 186-197.

Diamond, S., W.L Dolch, (1972), Generalized log-normal distribution of pore sizes in hydrated cement paste, Journal of Colloid and Interface Science, 38:1, 234-244, ISSN 0021-9797, http://dx.doi.org/10.1016/0021-9797(72)90239-1.

Douglas, J., (2007), Physical vulnerability modeling in natural hazard risk assessment, Nat. Hazards Earth Syst. Sci., 7, 283-228

Duguid, A., R. Butsch, J.W. Carey, M. Celia, N. Chugunov, S. Gasda, T.S. Ramakrishnan, V. Stamp, J. Wang, (2013), Pre-injection Baseline Data Collection to Establish Existing Wellbore Leakage Properties, GHGT-11 Proceedings of the 11th International Conference on Greenhouse Gas Control Technologies, 18-22 November 2012, Kyoto, Japan, Energy Procedia, 37, 5661-5672, doi:10.1016/j.egypro.2013.06.488. 
Duguid, A., R.J. Butsch, M. Loizzo, V. Stamp, (2011), Collection of baseline wellbore cement data in multiple wells in the same field, 10th International Conference on Greenhouse Gas Control Technologies, Energy Procedia, 4, 5130-5137, http://dx.doi.org/10.1016/j.egypro.2011.02.489.

Gasda, S.E., M.A. Celia, J.Z. Wang, A. Duguid, (2013), Wellbore Permeability Estimates from Vertical Interference Testing of Existing Wells, GHGT-11 Proceedings of the 11th International Conference on Greenhouse Gas Control Technologies, 18-22 November 2012, Kyoto, Japan, Energy Procedia, 37, 5673-5680, doi:10.1016/j.egypro.2013.06.489.

Gaull, B.A., M.O. Michael-Leiba, J.M.W. Rynn, (1990), Probabilistic earthquake risk maps of Australia, Australian Journal of Earth Sciences, 37:2, 169-187, $10.1080 / 08120099008727918$

Hou, Z., D.H. Bacon, D.W. Engel, G. Lin, Y. Fang, H. Ren, Z. Fang, (2016), Uncertainty analyses of $\mathrm{CO}_{2}$ plume expansion subsequent to wellbore $\mathrm{CO}_{2}$ leakage into aquifers, International Journal of Greenhouse Gas Control, 27, 69-80, 10.1016/j.ijggc.2014.05.004.

Hulme, P. E., (2009), Trade, transport and trouble: managing invasive species pathways in an era of globalization. Journal of Applied Ecology, 46: 10-18. doi:10.1111/j.13652664.2008.01600.x

IEA (2009). Energy Technology Transitions for Industry. Strategies for the Next Industrial Revolution. International Energy Agency, Paris. IPCC (2014). Climate Change 2014: Mitigation of Climate Change. Contribution of Working Group III to the Fifth Assessment Report of the Intergovernmental Panel on Climate Change. Cambridge University Press, Cambridge, United Kingdom and New York, NY, USA. 
Keating, E. D. Bacon, S. Carroll, K. Mansoor, Y. Sun, L. Zheng, D. Harp, Z. Dai, (2016), Applicability of aquifer impact models to support decisions at $\mathrm{CO}_{2}$ sequestration sites. International Journal of Greenhouse Gas Control, 52, 319-330, 10.1016/j.ijggc.2016.07.001.

Last, G.V., C.J. Murray, Y. Bott, (2016), Derivation of groundwater threshold values for analysis of impacts predicted at potential carbon sequestration sites, International Journal of Greenhouse Gas Control 49:138-148, 10.1016/j.ijggc.2016.03.004.

Little, M. G., R. B. Jackson, (2010). Potential Impacts of Leakage from Deep $\mathrm{CO}_{2}$ Geosequestration on Overlying Freshwater Aquifers. Environmental Science \& Technology 44(23): 9225-9232.

Moffett, A., N. Shackelford, S. Sarkar, (2007), Malaria in Africa: Vector Species' Niche Models and Relative Risk Maps. PLoS ONE 2(9): e824. doi:10.1371/journal.pone.0000824

Navarre-Sitchler, A. K., R. M. Maxwell, E. R. Siirila, G. E. Hammond, P. C. Lichtner, (2013), Elucidating geochemical response of shallow heterogeneous aquifers to $\mathrm{CO}_{2}$ leakage using high-performance computing: Implications for monitoring of $\mathrm{CO}_{2}$ sequestration. Advances in Water Resources 53(0): 45-55. doi:10.1016/j.advwatres.2012.10.005.

Nicot, J.P., Oldenburg, C.M., Bryant, S.L., S.D. Hovorka, (2008), Pressure Perturbations from Geologic Carbon Sequestration: Area-of-Review Boundaries and Borehole Leakage Driving Forces, in Proceedings 9th International Conference of Greenhouse Gas Control Technologies, Washington, USA, November 2008.

Nordbotten J.M., D. Kavetski, M. Celia, S. Bachu, (2009), Model for $\mathrm{CO}_{2}$ Leakage Including Multiple Geological Layers and Multiple Leaky Wells, Environ. Sci. Technol., 43, 743749. 
Oldenburg, C. M., A. Cihan, Q. Zhou, S. Fairweather, L.H. Spangler, (2016), Geologic carbon sequestration injection wells in overpressured storage reservoirs: estimating area of review. Greenhouse Gas Sci Technol. doi:10.1002/ghg.1607

Pawar, R.J., G.S. Bromhal, S.P. Chu, R.M. Dilmore, C.M. Oldenburg, P.H. Stauffer, Y.Q. Zhang, G.D. Guthrie, (2016), The National Risk Assessment Partnership's integrated assessment model for carbon storage: A tool to support decision making amidst uncertainty, International Journal of Greenhouse Gas Control 52:175-189, 10.1016/j.jggc.2016.06.015.

Phillips, S.L., A. Igbene, J.A. Fair, H. Ozbek, M. Tavana, (1981), A technical data-book for geothermal energy utilization. Lawrence Berkeley National Laboratory.

Siirila, E. R., A. K. Navarre-Sitchler, R. M. Maxwell, J. E. McCray, (2012), A quantitative methodology to assess the risks to human health from $\mathrm{CO}_{2}$ leakage into groundwater. Advances in Water Resources 36(0): 146-164. doi:10.1016/j.advwatres.2010.11.005.

Spivey, J. P., W.D. Mccain, R. North, (2004), Estimating Density, Formation Volume Factor, Compressibility, Methane Solubility, and Viscosity for Oilfield Brines at Temperatures From 0 to $275^{\circ} \mathrm{C}$, Pressures to $200 \mathrm{MPa}$, and Salinities to $5.7 \mathrm{~mole} / \mathrm{kg}$, Journal of Canadian Petroleum.

U.S. EPA, (2013), Geologic Sequestration of Carbon Dioxide Underground Injection Control (UIC) Program Class VI Well Area of Review Evaluation and Corrective Action Guidance. Office of Water (4606M), EPA 816-R-13-005.

Varadharajan, C., R.M. Tinnacher, J.D. Pugh, R.C. Trautz, L. Zheng, N.F. Spycher, J.T. Birkholzer, H. Castillo-Michel, R.A. Esposito, P.S. Nico, (2013), A laboratory study of the initial effects of dissolved carbon dioxide $\left(\mathrm{CO}_{2}\right)$ on metal release from shallow 
sediments, International Journal of Greenhouse Gas Control, 19, 183-211, 10.1016/j.ijggc.2013.08.017.

Venette, R.C., D.J. Kriticos, R.D. Magarey, F.H. Koch, R.H.A. Baker, S.P. Worner, N.N. G. Raboteaux, D.W. McKenney, E.J. Dobesberger, D. Yemshanov, P.J. De Barro, W.D. Hutchison, G. Fowler, T.M. Kalaris, J. Pedlar, (2010), Pest Risk Maps for Invasive Alien Species: A Roadmap for Improvement. BioScience, 60 (5): 349-362. doi: 10.1525/bio.2010.60.5.5

Watson, T.L., and S. Bachu, (2008), Identification of Wells With High $\mathrm{CO}_{2}$-Leakage Potential in Mature Oil Fields Developed for CO2-Enhanced Oil Recovery. SPE Symposium on Improved Oil Recovery, 20-23 April, Tulsa, Oklahoma, USA. http://dx.doi.org/10.2118/112924-MS

Xiao, T., B. McPherson, F. Pan, R. Esser, W. Jia, A. Bordelon, D. Bacon, (2016), Potential chemical impacts of $\mathrm{CO}_{2}$ leakage on underground source of drinking water assessed by quantitative risk analysis, International Journal of Greenhouse Gas Control 50:305-316, 10.1016/j.ijggc.2016.04.009.

Zheng, L., N. Spycher, C. Varadharajan, R.M. Tinnacher, J.D. Pugh, M. Bianchi, J. Birkholzer, P.S. Nico, R.C. Trautz, (2015), On the mobilization of metals by $\mathrm{CO}_{2}$ leakage into shallow aquifers: exploring release mechanisms by modeling field and laboratory experiments. Greenhouse Gas Sci Technol, 5: 403-418. doi:10.1002/ghg.1493.

Zhong, L., K.J. Cantrell, D.H. Bacon, J. Shewell, (2014), Transport of organic contaminants mobilized from coal through sandstone overlying a geological carbon sequestration reservoir, International Journal of Greenhouse Gas Control, 21, 158-164, 10.1016/j.ijggc.2013.12.014. 
a)
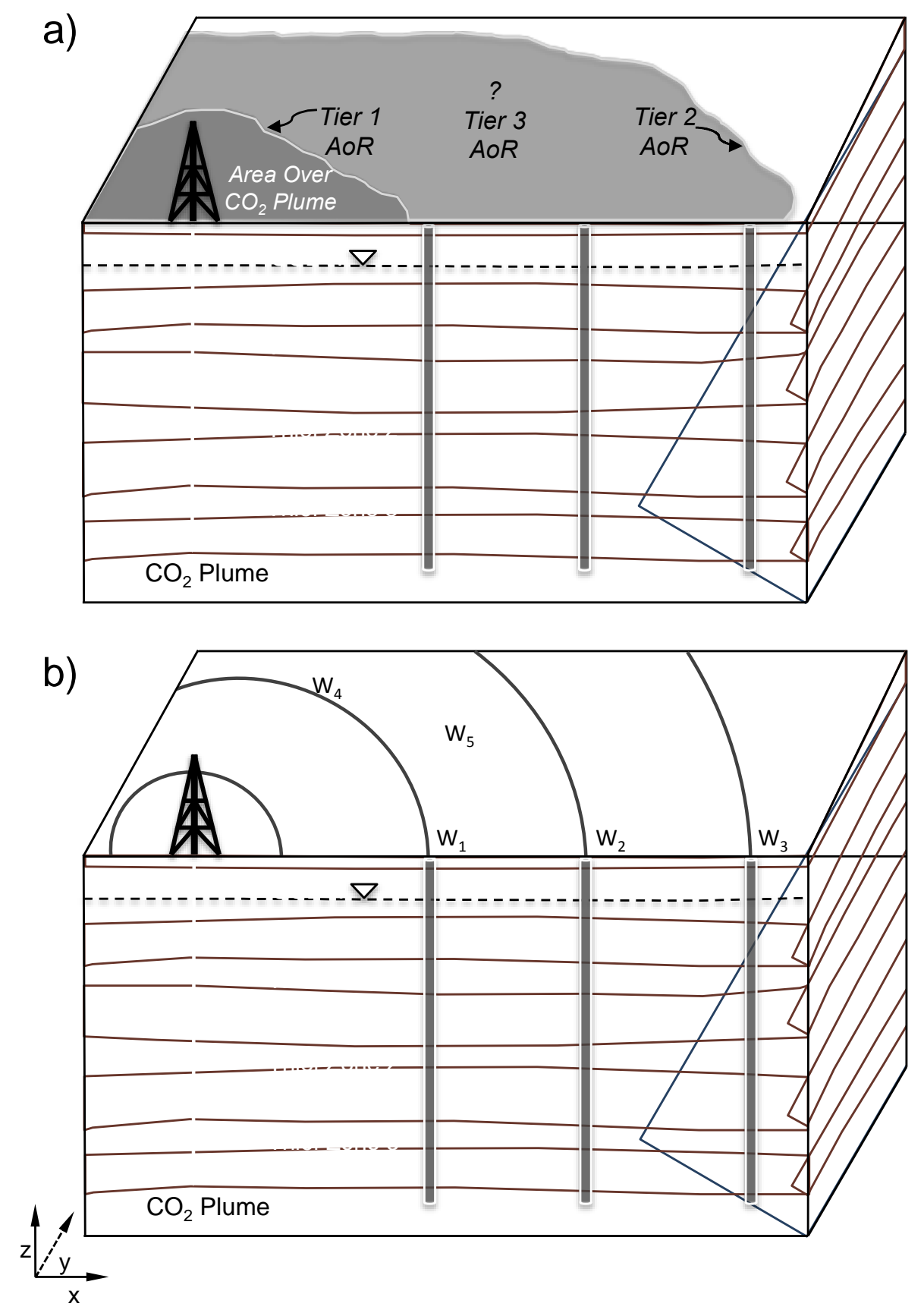

Figure 1. a) Schematic of the three tiers of AoR described by Birkholzer et al., 2014; b) example leaky well points sampled $\left(\mathrm{W}_{1}, \mathrm{~W}_{2}, \mathrm{~W}_{3}\right)$ and interpolated $\left(\mathrm{W}_{4}, \mathrm{~W}_{5}\right)$ in risk map methodology. 
Step 1: Numerical Simulations or Analytical Solutions

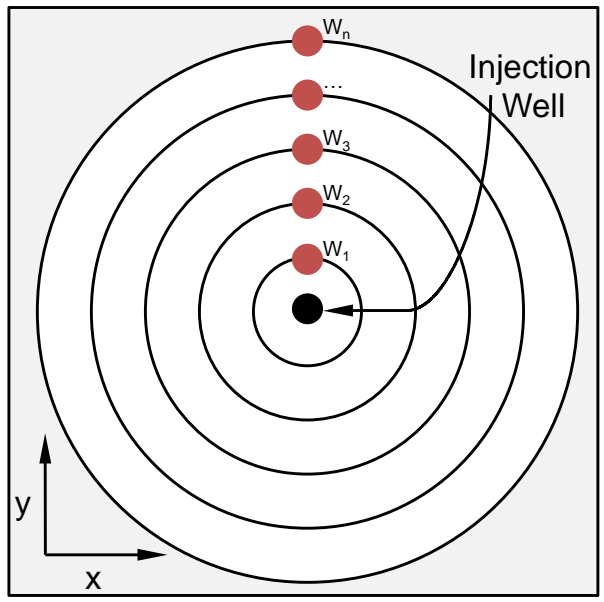

Step 3: Generate Spatial Probability Distributions of $\mathrm{Vol}_{\text {imp }}$

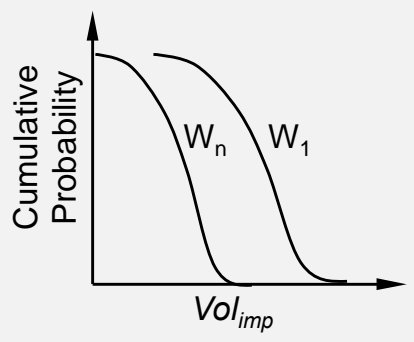

Use the theory of "functions of a random variable" to generate probability distribution at each location
Step 2: Determine Distributions
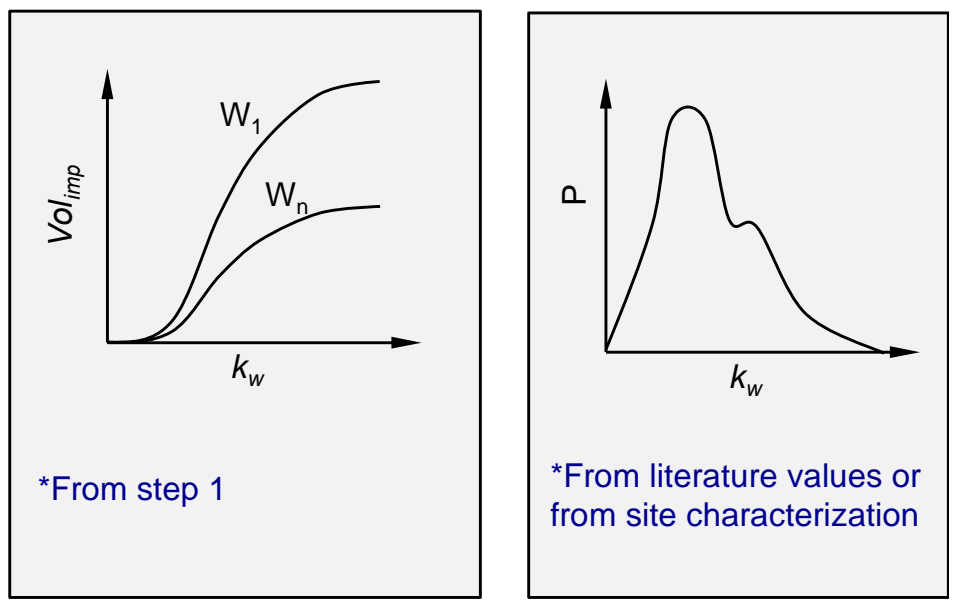

Step 4: Generate Probabilistic Risk Maps

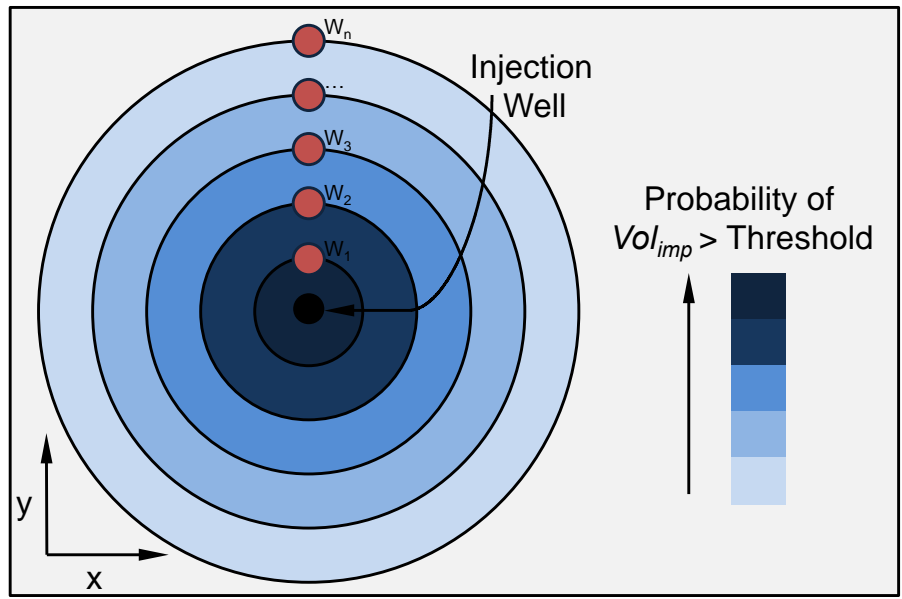

Figure 2. Schematic of the four steps required in the risk map methodology using the functions of a random variable approach. Note that this procedure is repeated as a function of time. 

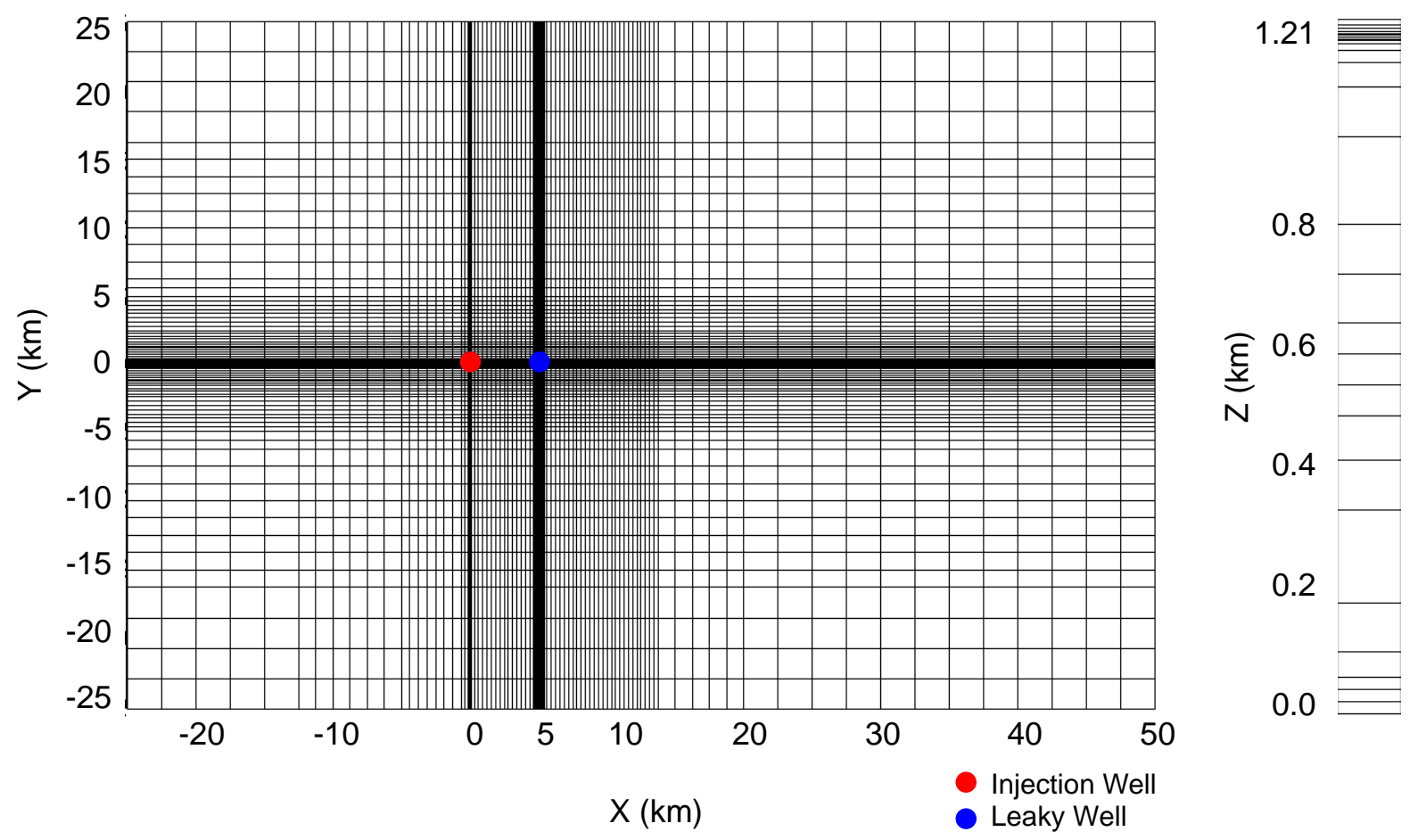

Figure 3. Spatial extents and example discretization of numerical model domain for leaky well distance 1 (leaky well at $X=5 \mathrm{~km}$ ). Note the location of the injection well is constant for all simulations. 


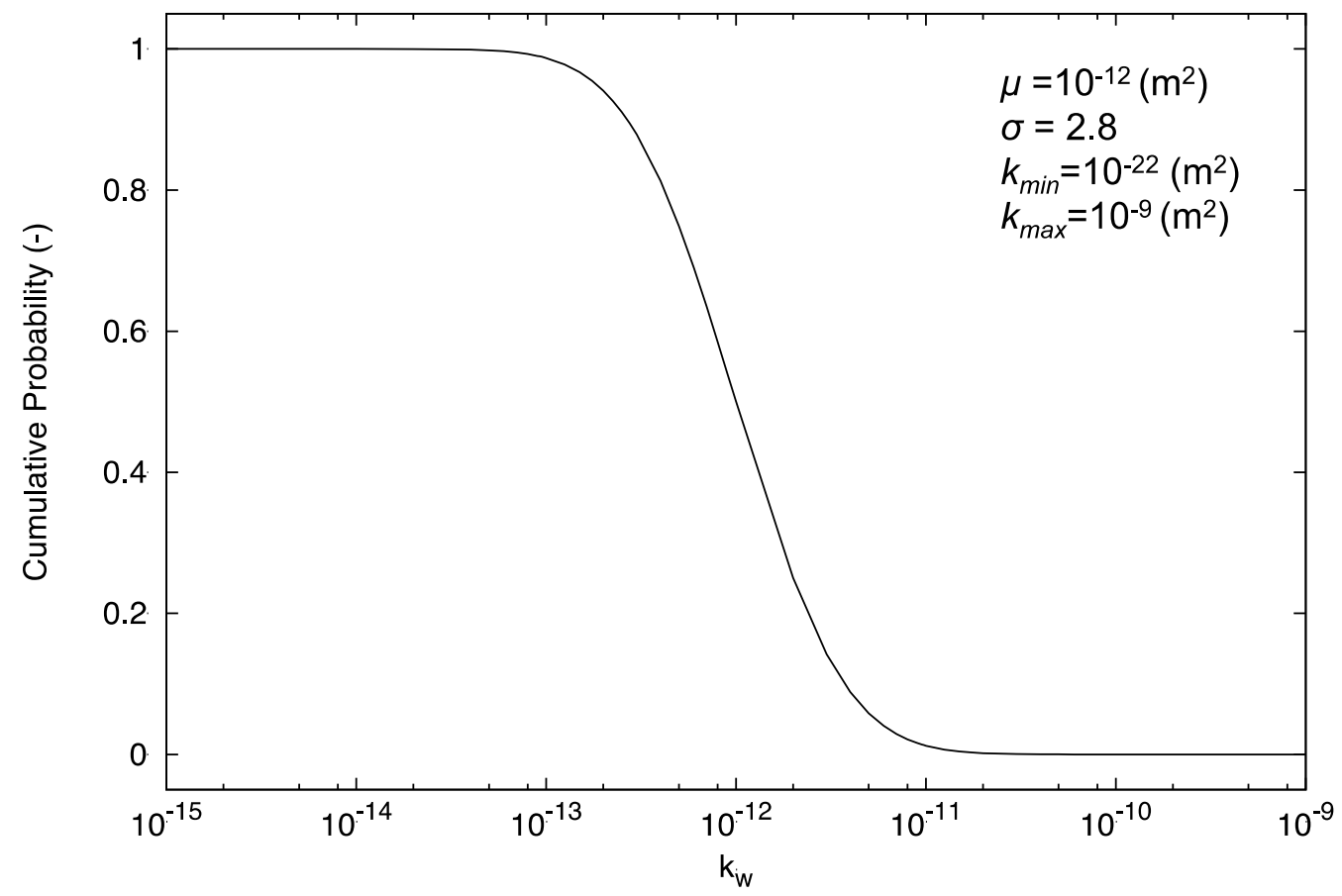

Figure 4. The generalized lognormal distribution used in the example demonstration, shown as a cumulative distribution function as evaluated with equation (6). 
a) 30 (y)

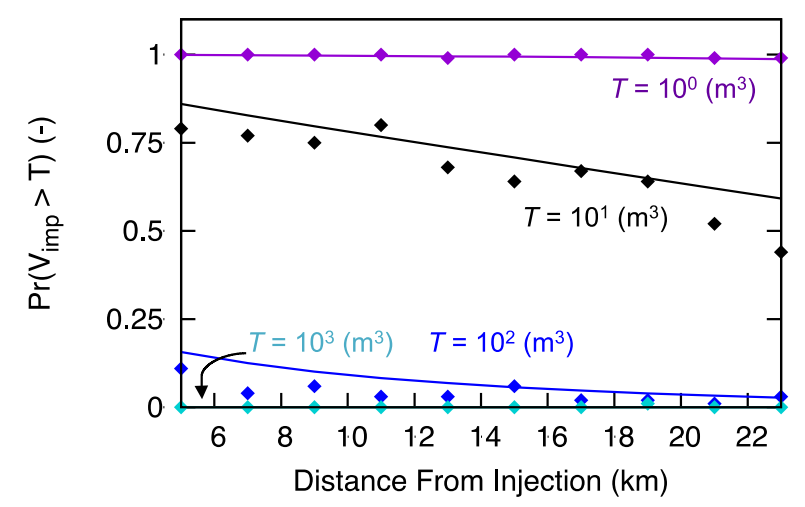

b) 200 (y)

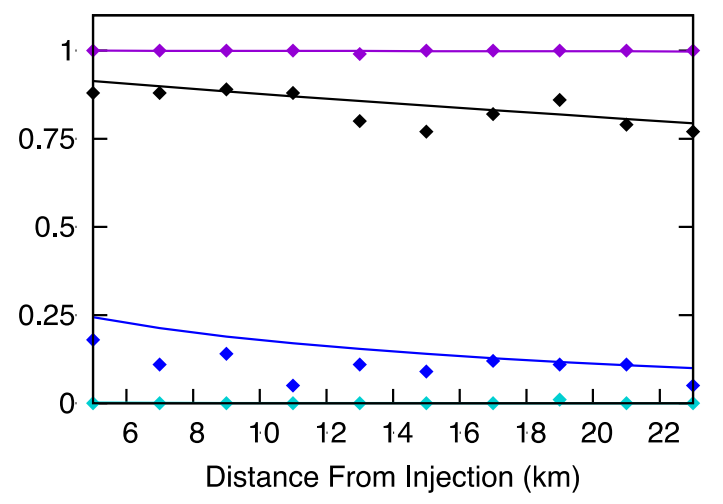

Figure 5. 1D transects of probabilistic risk maps comparing results obtained with the functions of a random variable solution (lines) and the Monte Carlo solution (symbols) at a) the end of injection (30 y) and b) $200(y)$. 


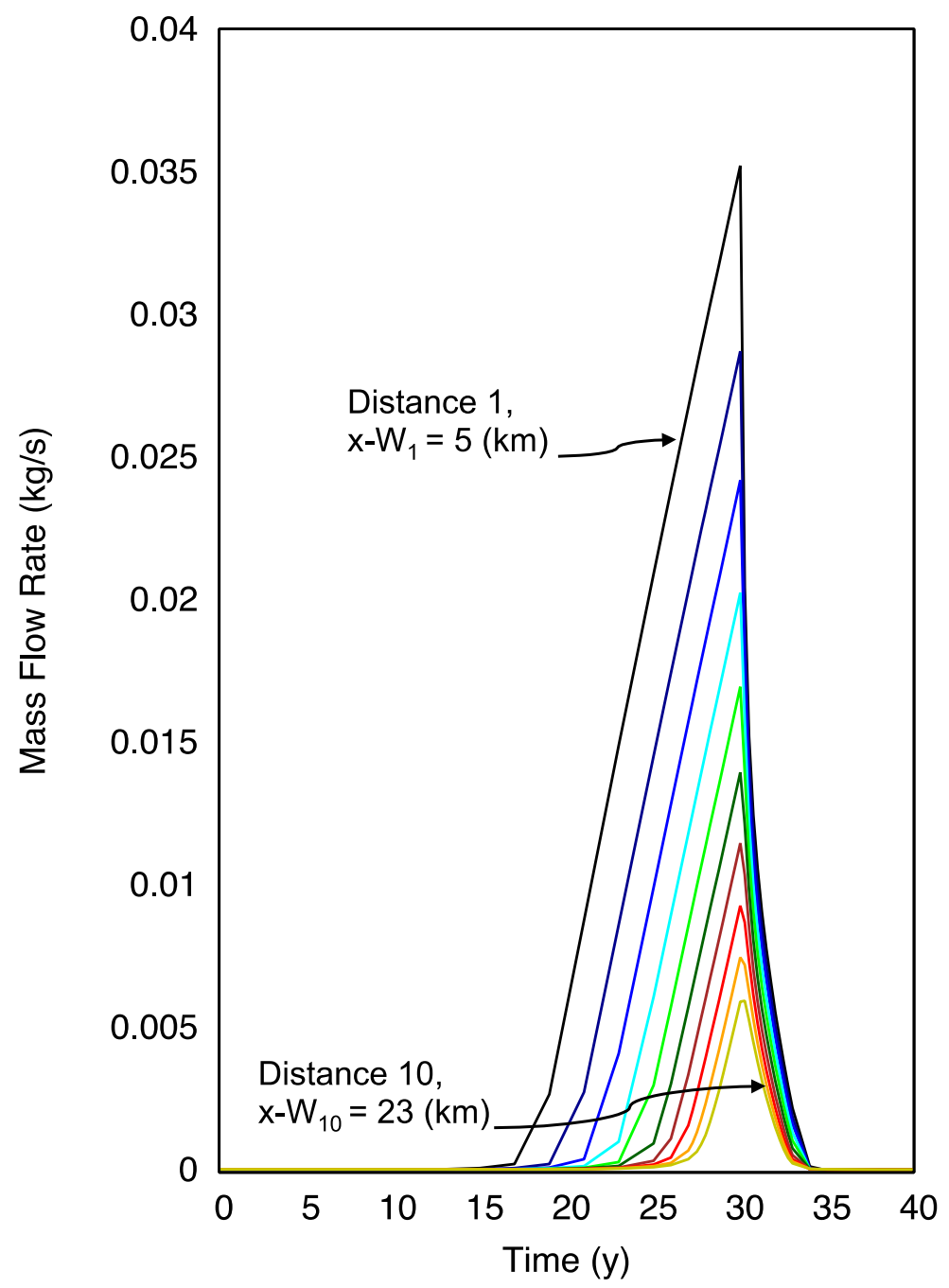

Figure 6. Example leaky well vertical mass flow rates at the interface between the caprock unit and the USDW (leaky well permeability $=10^{-9}\left(\mathrm{~m}^{2}\right)$ only shown). Note that mass flow rates between approximately 35-200 (y) are nearly zero. 

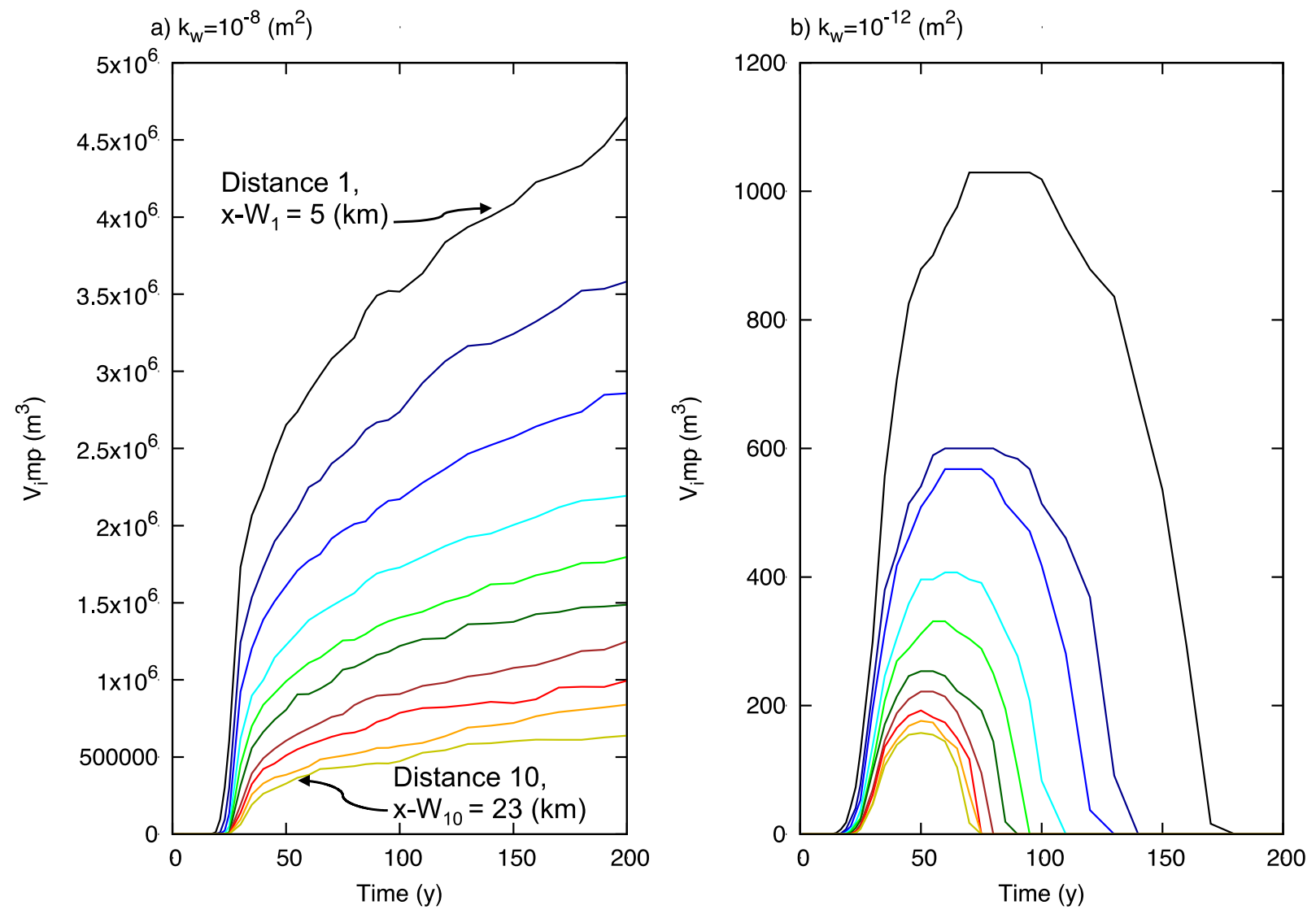

Figure 7. Volume of impacted water for well permeabilities of a) $10^{-8}\left(\mathrm{~m}^{2}\right)$ and b) $10^{-12}\left(\mathrm{~m}^{2}\right)$. Note the magnitude differences between the two y-axes. 


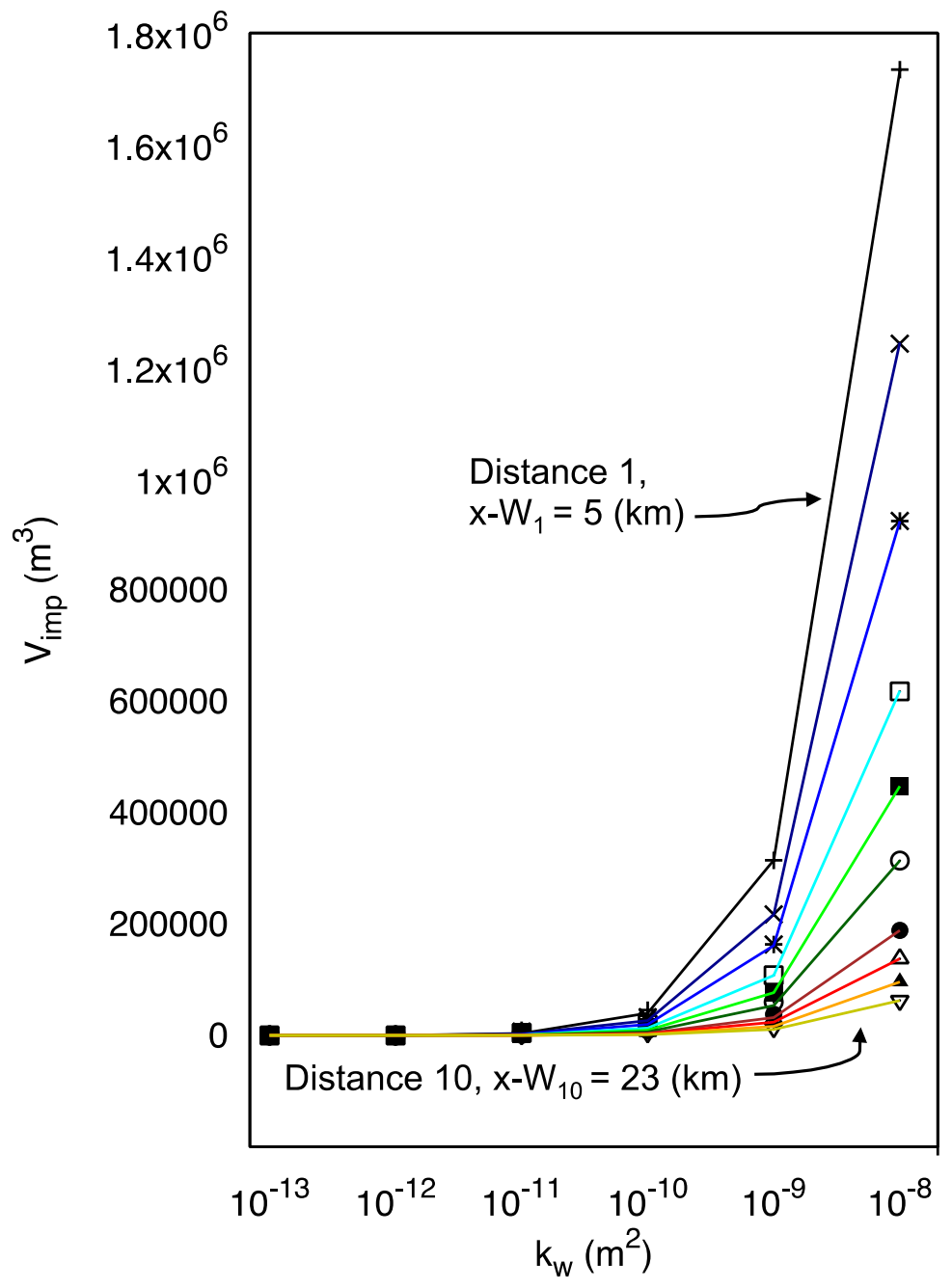

Figure 8. Example functional fit of the impacted USDW water volume as a function of well permeability at the end of injection $(30 \mathrm{y})$. In this example, estimated parameters are approximately as follows: $a=21.7(-), b=-1.0(-), c=3.1(-), d=-12.3(-)$. 


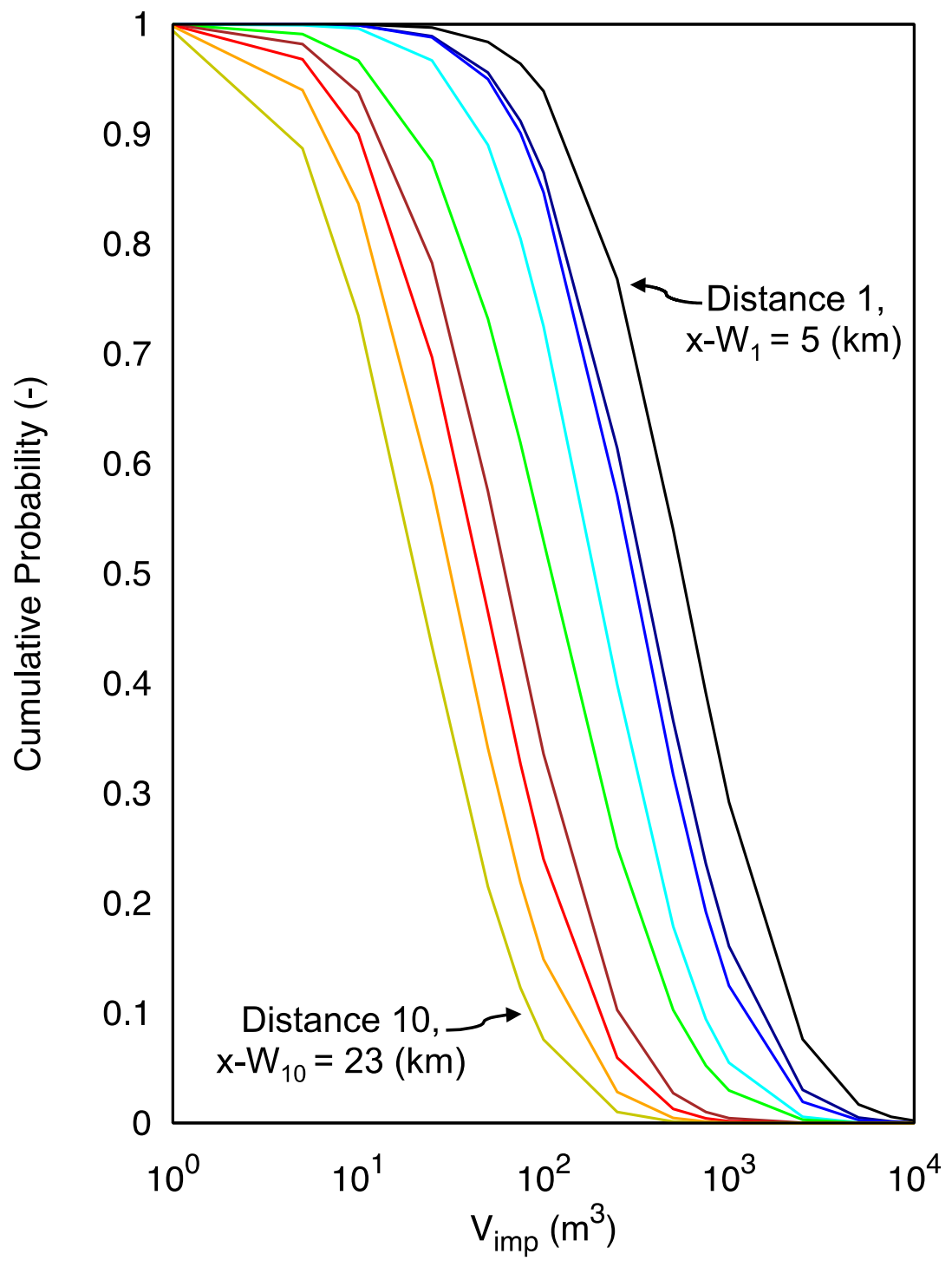

Figure 9. Example CDF of impacted USDW water volume for different leaky well distances at the end of injection (30 y). 
a) $15(y)$

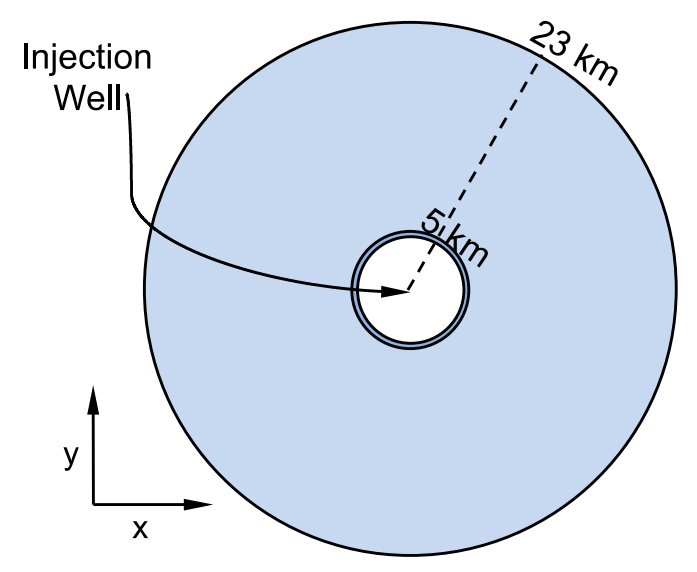

c) $45(\mathrm{y})$

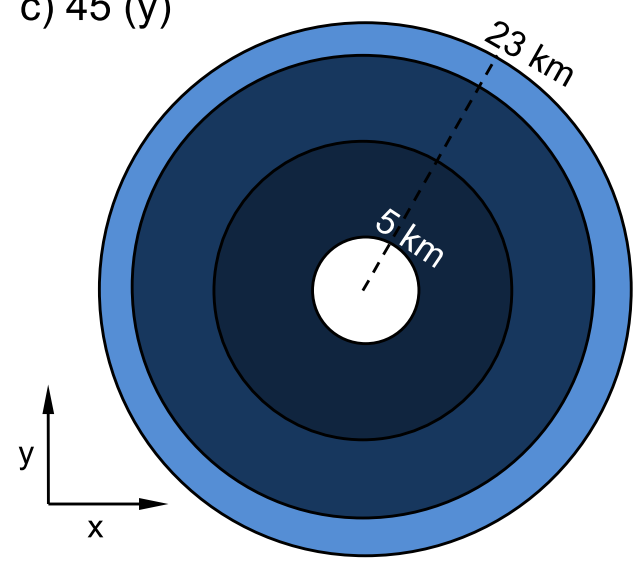

b) 30 (y)

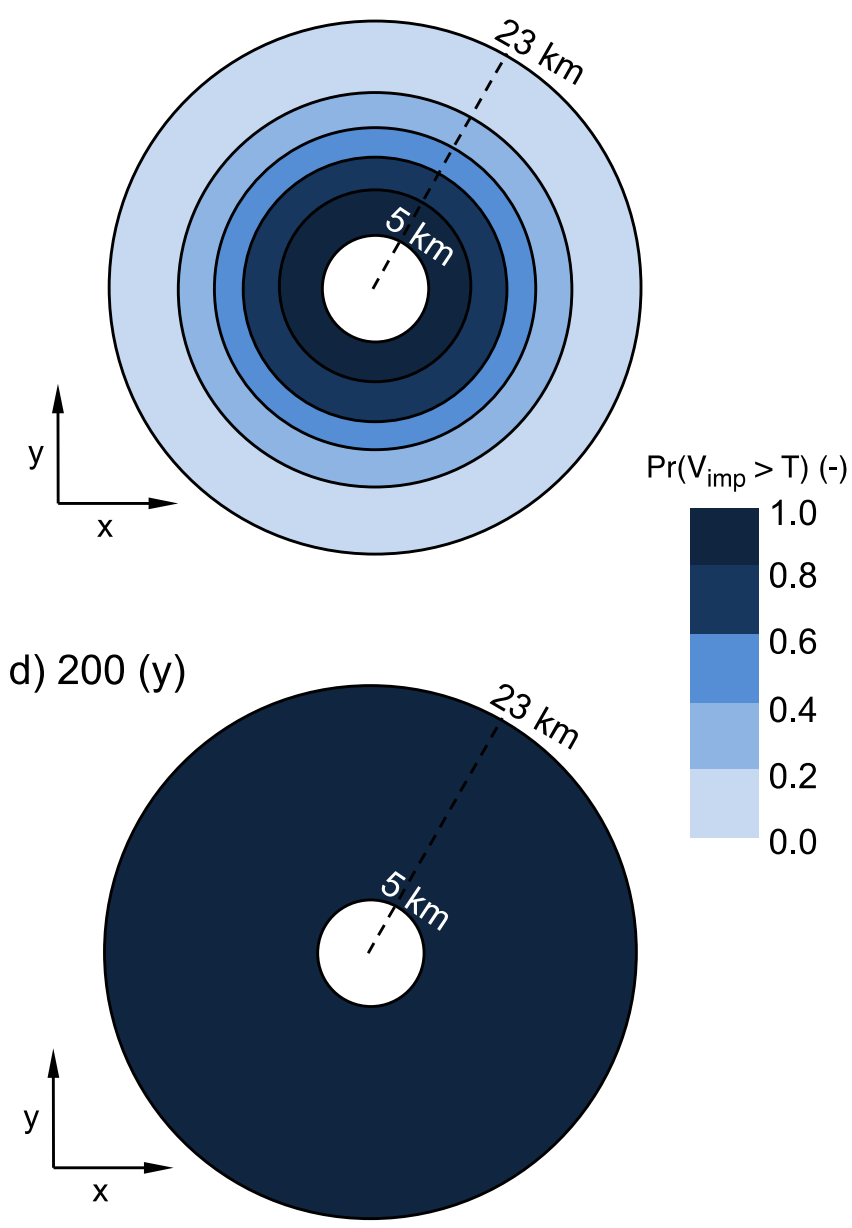

Figure 10. Probabilistic risk maps for a $V_{\text {imp }}$ threshold equivalent to $T=10^{2}\left(\mathrm{~m}^{3}\right)$ evolving over time a) during injection at $15(\mathrm{y}), \mathrm{b})$ at the end of injection at $30(\mathrm{y})$, and post injection at c) 45 (y), and d) 200 (y). Tier 3 area of review calculations span between distances of $5(\mathrm{~km})$ and 23 $(\mathrm{km})$, the color portions of the maps. 
a) $15(y)$

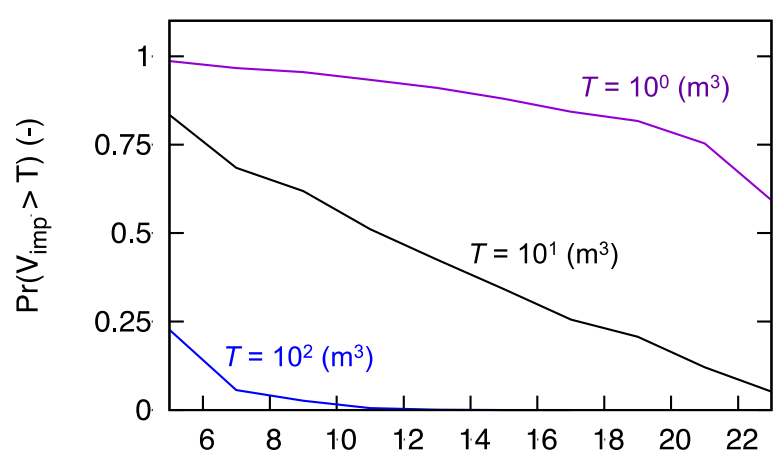

c) $45(y)$

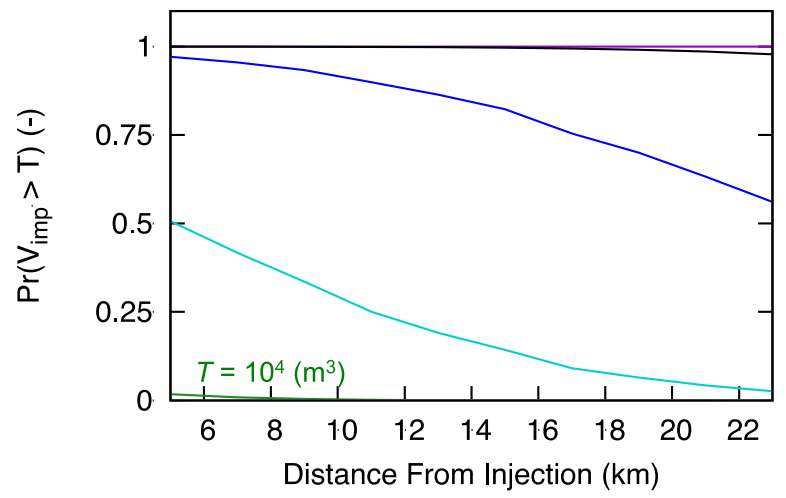

b) 30 (y)

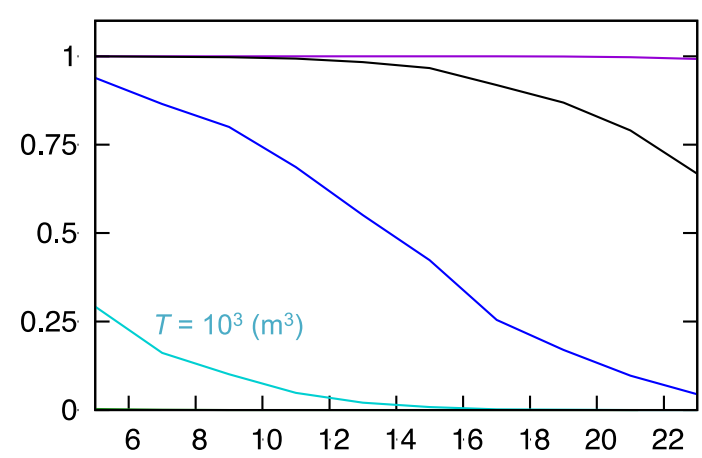

d) $200(y)$

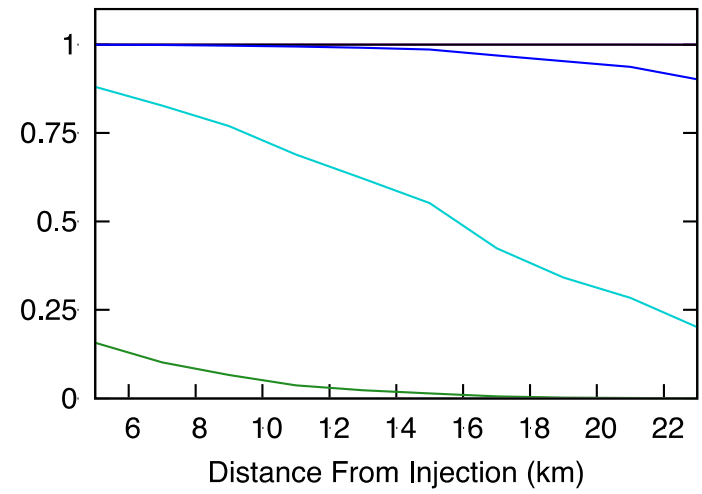

Figure 11. 1D transects of probabilistic risk maps for $V_{i m p}$ threshold equivalent to $T=10^{0}, 10^{1}$, $10^{2}, 10^{3}$, and $10^{4}\left(\mathrm{~m}^{3}\right)$ evolving over the same times shown in Figure 10. 


\begin{tabular}{|l|c|c|}
\hline Parameter & Value & Units \\
\hline Spatial Extent in the $\mathrm{x}, \mathrm{y}$, and $\mathrm{z}$ Directions (respectively) & $75,50,1.12$ & $(\mathrm{~km})$ \\
\hline Domain Porosity & 0.2 & $(-)$ \\
\hline Permeability - Reservoir & $10^{-12}$ & $\left(\mathrm{~m}^{2}\right)$ \\
\hline \multicolumn{1}{|c|}{ Caprock } & $10^{-18}$ & $\left(\mathrm{~m}^{2}\right)$ \\
\hline \multicolumn{1}{|c|}{ USDW } & $10^{-12}$ & $\left(\mathrm{~m}^{2}\right)$ \\
\hline $\mathrm{CO}_{2}$ Injection Rate & 10,000 & $(\mathrm{~T} / \mathrm{d})$ \\
\hline Equivalent Brine Injection Rate & $1.46 \times 10^{7}$ & $(\mathrm{~kg} / \mathrm{d})$ \\
\hline $\mathrm{CO}_{2}$ Density & 819 & $\left(\mathrm{~kg} / \mathrm{m}^{3}\right)$ \\
\hline Brine Density & 1195 & $\left(\mathrm{~kg} / \mathrm{m}^{3}\right)$ \\
\hline $\begin{array}{l}\text { Leaky Well Permeability Values }(6 \text { at order of magnitude } \\
\text { intervals) }\end{array}$ & $10^{-8}, 10^{-9}, 10^{-10}$ & $\left(\mathrm{~m}^{2}\right)$ \\
\hline Distance Between Leaky Wells & $10^{-11}, 10^{-12}, 10^{-13}$ & \\
\hline Land surface temperature & 2 & $(\mathrm{~km})$ \\
\hline
\end{tabular}

Table 1. Numerical simulation parameters for example demonstration. 